\title{
Reovirus Inhibits Poliovirus Replication upon Superinfection
}

\author{
Angila Ataei Pirkooh ${ }^{\mathrm{a}}$ Mahmoud Shamsi Shahrabadi $^{\mathrm{a}}$ Hamidreza Monavari $^{\mathrm{a}}$ \\ Abbas Shafiei $^{b}$ \\ ${ }^{a}$ Department of Virology, Faculty of Medicine, Iran University of Medical Sciences, Tehran, and bazi Vaccine and \\ Serum Institute, Karaj, Iran
}

\section{Key Words}

Poliovirus $\cdot$ Reovirus $\cdot$ Interference $\cdot$ Coinfection the growth of poliovirus upon superinfection. This phenomenon could be important to consider when using attenuated poliovirus vaccine.

Copyright $\odot 2011$ S. Karger AG, Basel

\begin{abstract}
Objective: Viral interference has been demonstrated in different systems, such as the effect of enterovirus infection on live-attenuated oral polio vaccine. In this study, the effect of reovirus which could exist in the human intestinal tract on poliovirus vaccine strains was investigated and could be an important factor to consider in oral polio vaccination. Methods: Cells were infected with reovirus, then superinfected with poliovirus. The amount of viral yields was measured by the $\mathrm{TCID}_{50}$ and plaque assay methods. Polioviral RNA synthesis was studied by real-time RT-PCR and the viral RNA load was calculated. Viral protein synthesis was determined using the techniques of immunoflourescent staining and PAGE followed by the immunoblotting experiment. $\boldsymbol{R} \boldsymbol{e}$ sults: Poliovirus superinfection of reovirus-infected cells resulted in inhibition of poliovirus replication. It was found that the inhibitory effect of reovirus was after establishment of its infection ( $2 \mathrm{~h}$ postinfection). There was no competition between the two viruses for cell attachment but poliovirus RNA and protein synthesis were inhibited. Conclusion: Infection of cells with reovirus could interfere with
\end{abstract}

\section{Introduction}

The phenomenon of viral interference or the inhibition of virus growth by another virus has been well known for several viruses and the mechanism of such a phenomenon has been partly described [1, 2]. Interference has been described in certain systems such as: serial passages of viruses at high MOI, resulting in accumulation of defective interfering viruses $[3,4]$, mixed infection of wild-type viruses with certain temperature-sensitive mutants $[5,6]$, coinfection of cells with different wildtype virus isolates $[7,8]$ and coinfection of cells with a different genus of viruses belonging to the same or a different family of viruses. An example of such interference is the effect of enterovirus infection with live-attenuated poliovirus vaccine resulting in inefficiency of vaccine-induced protection $[9,10]$. Also, the combination of hepatitis $A$ and $B$ vaccine has shown that the hepatitis B portion of the vaccine did not produce a clinically acceptable

\section{KARGER \\ Fax +4161306 1234 \\ E-Mail karger@karger.ch}

www.karger.com (c) 2011 S. Karger AG, Basel

$0300-5526 / 12 / 0551-0062 \$ 38.00 / 0$

Accessible online at: www.karger.com/int
Mahmoud Shamsi Shahrabadi, PhD

Department of Virology, Faculty of Medicine

Iran University of Medical Sciences

Tehran (Iran)

Tel. +9821 886022 05, E-Mail Mshahrabadi@hotmail.com 
antibody due to immunologic interference $[11,12]$. The other example is the effect of reovirus on environmental detection of enteroviruses [13].

In this study, we have examined coinfection of cells with reovirus and poliovirus. These viruses can coexist in the alimentary tract and their interference might have some impact on the outcome of their infection or may result in inefficiency of live-attenuated poliovirus vaccine. In this study, we report the results of experiments obtained from intracellular coinfection of cells with reovirus and poliovirus.

\section{Materials and Methods}

\section{Cells and Viruses}

Murine L929 cells were used for reovirus propagation. Stock cultures of L929 cells were grown in monolayers in Joklik's modified Eagle's essential medium (SMEM) supplemented with 5\% fetal bovine serum (Gibco). Vero cells were used for growth of poliovirus and were grown in Dulbecco's minimal essential medium (DMEM) containing 5\% fetal bovine serum. All cells were grown at $37^{\circ}$ in an atmosphere containing $5 \% \mathrm{CO}_{2}$. Sabin poliovirus type 3 vaccine strain obtained from the Razi Vaccine and Serum Institute was propagated in vero cells and titrated by the plaque assay method [14]. Reovirus type 3 Dearing (T3D) was propagated in L929 cells and assayed by the TCID 50 procedure.

\section{Coinfection Experiments}

Vero cells were used for coinfection because they were susceptible to both poliovirus and reovirus. Coinfection experiments were carried out as follows: (a) monolayers of cells were coinfected simultaneously with an equal titer of reovirus and poliovirus at a MOI of 20; (b) monolayers of cells were infected with poliovirus (MOI of 20) and after $2 \mathrm{~h}$ incubation at $37^{\circ}$ the inoculum was removed and the cells were reinfected with reovirus (MOI of 20 ), and (c) monolayers of cells were infected with reovirus (MOI of 20) and after $2 \mathrm{~h}$ incubation at $37^{\circ}$ they were reinfected as above with poliovirus (MOI of 20). For control, monolayers of cells were similarly infected separately with poliovirus and reovirus.

All the infected cells were incubated in DMEM at $37^{\circ}$ in an atmosphere of $5 \% \mathrm{CO}_{2}$ and were continued until 3 passages. After $32 \mathrm{~h}$, infected cultures were harvested and freezed-thawed 3 times. After low-speed centrifugation the supernatant was used for viral assay.

\section{Virus Purification}

The virus was purified on a sucrose cushion followed by $\mathrm{CsCl}$ density gradient centrifugation. The reovirus was purified according to the method of Fulong et al. [see 15]. Briefly the virus was concentrated on a $40 \%$ sucrose cushion followed by CsCl density gradient centrifugation. The poliovirus was purified from the infected cell supernatant by pelleting the crude virus at 25,000 $\mathrm{rpm}$ for $2 \mathrm{~h}$. The concentrated, partially purified virus was further purified by $\mathrm{CsCl}$ density gradient centrifugation. The purity of the viral bond was tested morphologically by negative staining electron microscopy.

Interference between Poliovirus and Reovirus

\section{Preparation of Antisera}

Both purified poliovirus and reovirus were mixed separately with Freund's complete adjuvant and used to inoculate female New Zealand white rabbits. Three injections were given weekly and a booster dose was applied 3 weeks later. The animals were bled 10 days later and sera were prepared and stored at $-20^{\circ}$.

\section{Receptor Binding Competition}

Monolayers of cells were infected with reovirus at a MOI of 200 and kept at $4^{\circ}$ for $1 \mathrm{~h}$. The cells were washed 3 times with cold media and reinfected with poliovirus at a MOI of 20 and were kept for $1 \mathrm{~h}$ at $4^{\circ}$. The cells were washed similarly as above, harvested and resuspended in $0.5 \mathrm{ml}$ of PBS. The amount of viruses bound to the cells was determined by real-time RT-PCR assay.

In another experiment, cells were similarly infected first with poliovirus at a MOI of 200 and then reinfected with reovirus at a MOI of 20. The cells were then subjected to real-time RT-PCR assay as above. For control, cells were infected with reovirus and poliovirus separately at a MOI of 20 and similarly processed for viral load assay.

\section{PAGE of RNA}

Reovirus-infected cells were harvested after $24 \mathrm{~h}$. Cells were lysed by treatment with SDS and proteinase K and then RNA was extracted by phenol chloroform according to the standard method. Extracted RNA was electrophoresed on 10\% acrylamide gel. The RNA bonds were stained by ethidium bromide and visualized by UV light.

\section{Real-Time RT-PCR Method}

RNA was extracted according to the manufacturer's instructions (AccuPrep ${ }^{\mathrm{TM}}$; Bioneer, Alameda, Calif., USA). RNA was purified by passing through a spinning column. Oligonucleotide primers and probe were designed as follows: forward primers, 5'-CCCTGAATGCGGCTAATCC- $3^{\prime}$ and reverse primers, 5'-ATTGTCACCATAAGCAGCCA-3'. The probe was FAM 5'-AACCGACTACTACTTTGGGTGTCCGTGTTTC-3' BHQ1. The primers were designed from $5^{\prime} \mathrm{NTR}$ which is conserved and is specific for all enteroviruses. Using these primers will therefore detect enteroviruses including poliovirus.

Real-time RT-PCR was performed in accordance with the manufacturer's instructions (Life Technologies, Carlsbad, Calif., USA) in a 9600 DNA Thermocycler. PCR was performed with an initial cycle of $94^{\circ}$ for $10 \mathrm{~min}$ followed by 45 cycles at $94^{\circ}$ for $20 \mathrm{~s}$, $60^{\circ}$ for $40 \mathrm{~s}$, and $72^{\circ}$ for $40 \mathrm{~s}$. Samples were done by triple test. A negative control was processed after every fourth test tube.

\section{Analysis of Viral Proteins by SDS-PAGE}

Cells were infected with reovirus (MOI of 20) and after $2 \mathrm{~h}$ incubation at $37^{\circ}$ they were reinfected with poliovirus (MOI of $20)$. After $24 \mathrm{~h}$, the infected cells were harvested. The cells were scraped off the bottles and centrifuged for $10 \mathrm{~min}$ at low speed. A lysis mix was added to the pellet and after boiling they were electrophoresed on $10 \%$ polyacrylamide gel according to the method of Laemmli [16]. Purified reoviruses and polioviruses were similarly lysed and electrophoresed simultaneously. The protein bonds were visualized by Coomassie blue staining.

For immunoblotting the protein bonds in acrylamide gel were blotted onto nitrocellulose paper using a semi-dry blotter at 30 $\mathrm{mA}$ for $1 \mathrm{~h}$. The blotted proteins were treated with specific anti- 
sera and stained with anti-rabbit peroxidase conjugate using TMB as substrate.

\section{Immunofluorescent Staining}

Vero cells were grown in a monolayer on glass coverslips in a 24-well tissue culture dish. The cells were coinfected with reovirus and poliovirus as described. For control, cells were infected by either of the viruses separately. At various times after infection $(4,8,10,18 \mathrm{~h})$, coverslips were removed, washed in PBS and fixed in acetone at $-20^{\circ}$. The optimum time of postinfection for appearance of viral antigen was $10 \mathrm{~h}$ for poliovirus and $18 \mathrm{~h}$ for reovirus. They were stained indirectly with fluorescein-conjugated antirabbit IgG using specific viral antisera.

\section{Results}

\section{Virus Yield in Coinfected Cells by Reovirus and}

Poliovirus

Monolayers of vero cells were infected with reovirus and poliovirus at different times and conditions, as described in the Materials and Methods section. Controlinfected cells were infected with each of the two viruses at the same MOI and were incubated similarly. Virus assay was performed in the presence of neutralizing antisera, as described in the Materials and Methods section. Therefore, the cytopathic effect observed in the $\mathrm{TCID}_{50}$ assay in the presence of poliovirus antiserum was related to reovirus. As shown in figure 1, in the cells infected with reovirus for $2 \mathrm{~h}$ followed by reinfection with poliovirus after the first passage, there was a marked decrease in poliovirus production of about 7 logs as assayed by the $\mathrm{TCID}_{50}$ method. Similar results were obtained by plaque assay for poliovirus yield (fig. 2).

When the cells were infected with poliovirus followed by reinfection with reovirus, poliovirus multiplication was not affected, whereas the reovirus yield was decreased (fig. 1). Similar results were obtained in a simultaneous infection of cells by both poliovirus and reovirus, in which only the reovirus yield was decreased. These experiments were repeated with similar results. The decline in poliovirus replication was similar when the reovirusinfected cells were superinfected with poliovirus at $4 \mathrm{~h}$.

\section{Cell Attachment Competition between Reovirus and \\ Poliovirus}

In order to determine if the inhibitory effect of reovirus on poliovirus multiplication was due to cell attachment competition, infected cells were prepared as described in the Materials and Methods section and the amount of poliovirus bound to the cells was determined by the real-time RT-PCR technique. There was no sig-

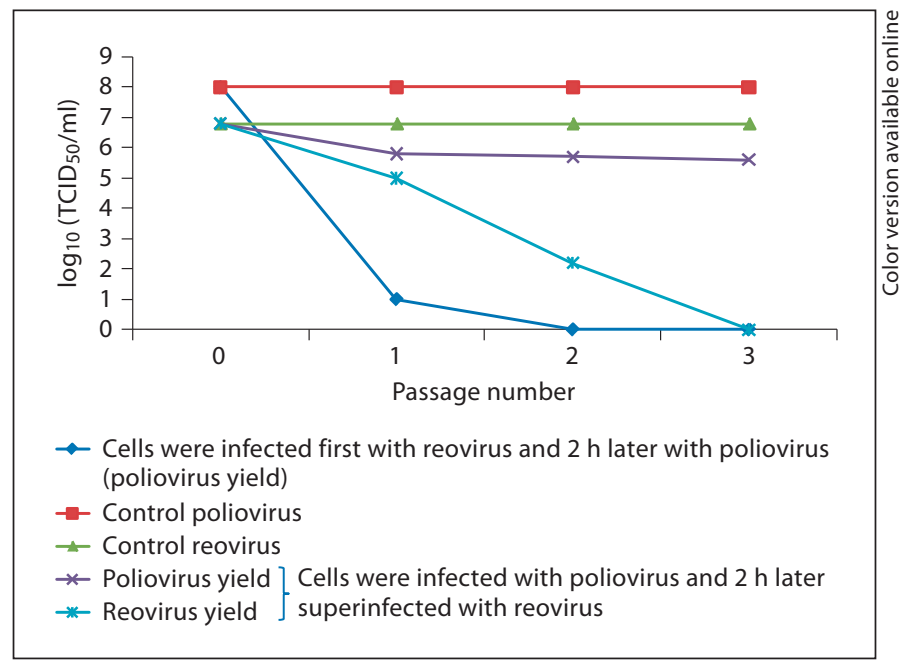

Fig. 1. Poliovirus and reovirus yield in coinfected cells. The infected cells were harvested and treated with reovirus antiserum (for poliovirus assay) or with poliovirus antiserum (for reovirus assay). After $32 \mathrm{~h}$, virus yield was determined by the $\mathrm{TCID}_{50}$ method. We used the harvest as seed viruses for infection as above in the second and third passages.

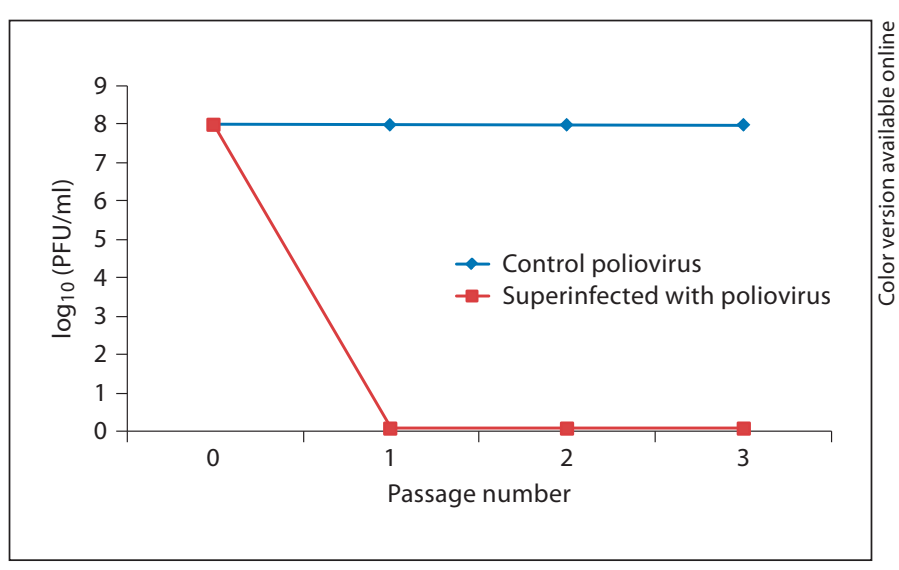

Fig. 2. Poliovirus yield in infected cells as in figure 1 and assayed by the plaque assay method.

nificant difference in poliovirus cell attachment in the presence or absence of reovirus. In preadsorbed cells with reovirus, the number of poliovirus particles attached per 30 cells was 480 as determined by real-time RT-PCR and the attached poliovirus particles was 630 in cells preadsorbed with poliovirus. In control cells (only adsorbed with poliovirus), this number was 530. This observation indicated that there was no receptor compe- 

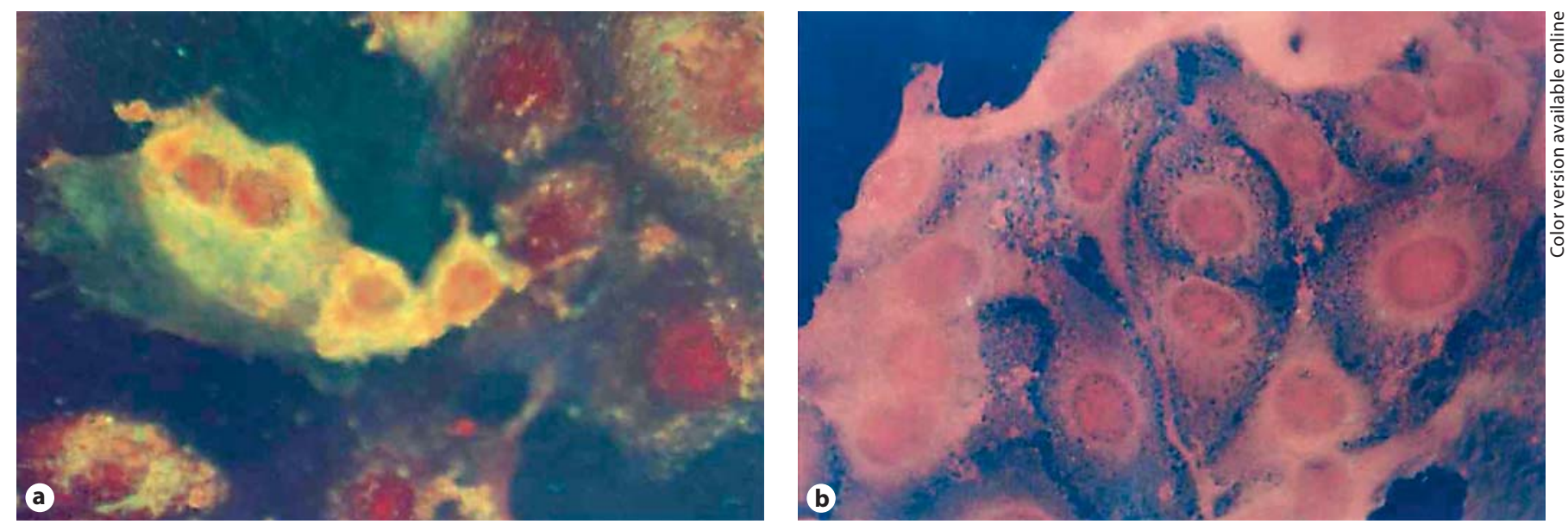

Fig. 3. a Reovirus antigens in coinfected cells. Reovirus-infected cells were superinfected with poliovirus and stained with fluorescein-conjugated antibody using reovirus-specific antiserum. Viral antigens are present inside the cytoplasm. b Similar infected cells as in a were stained with the conjugate using poliovirus-specific antiserum. No staining of the cytoplasm demonstrated absence of poliovirus antigen.

Table 1. Poliovirus RNA synthesis in superinfected cells

\begin{tabular}{lrr}
\hline Experiment & Sample 1 & Sample 2 \\
\hline $\begin{array}{l}\text { Reovirus infection followed by } \\
\text { 2 h superinfection with poliovirus }\end{array}$ & & \\
\hline $\begin{array}{l}\text { Simultaneous infection with reovirus } \\
\text { and poliovirus }\end{array}$ & 810,450 & 844,810 \\
\hline $\begin{array}{l}\text { Poliovirus infection followed by } \\
\text { 2 h superinfection with reovirus }\end{array}$ & 900,000 & 783,100 \\
\hline
\end{tabular}

Values are copy numbers of poliovirus per milliliter.

tition between the two viruses. Similar results were obtained when cells were treated with a high MOI of poliovirus followed by reinfection with reovirus. The reovirus was determined by the TCID $_{50}$ method (data not shown).

\section{Viral RNA Synthesis}

RNA from coinfected cells was extracted and analyzed by real-time RT-PCR to determine the polioviral RNA load in coinfected cells. As shown in the results of the two experiments in table 1, the load of poliovirus is very low in the cells which were first infected by reovirus and then by poliovirus. In these cells reovirus RNA was synthesized similarly to control reovirus-infected cells and could be detected by gel electrophoresis.

Interference between Poliovirus and Reovirus

\section{Viral Protein Synthesis in Coinfected Cells}

In order to determine if the viral antigens are synthesized and accumulated in coinfected cells, infected cells were stained by fluorescein-conjugated antibodies using viral-specific antisera. As shown in figure 3, in reovirusinfected cells coinfected with poliovirus, there was no detectable poliovirus antigen using poliovirus-specific antisera, whereas when reovirus antiserum was used, viral antigens were present in the cytoplasm of coinfected cells. These results indicated that poliovirus protein synthesis was inhibited in cells previously infected with reovirus. A similar observation was made in a Western blotting experiment: when similarly coinfected cells were subjected to PAGE followed by Western blotting, no detectable poliovirus antigens were observed whereas reovirus antigens were present (fig. 4).

\section{Discussion}

Interference between viruses belonging to the same family or between members of unrelated ones upon coinfection of cells has been reported $[17,18]$. Generally, infection of a cell with two viruses could result in growth and maturation of both viruses, which might be beneficial to one of the viruses such as coinfection by adenovirus and adeno-associated viruses. Coinfection could also end up in growth inhibition of one of the viruses by the other, such as infection of cells with enteroviruses, which would 


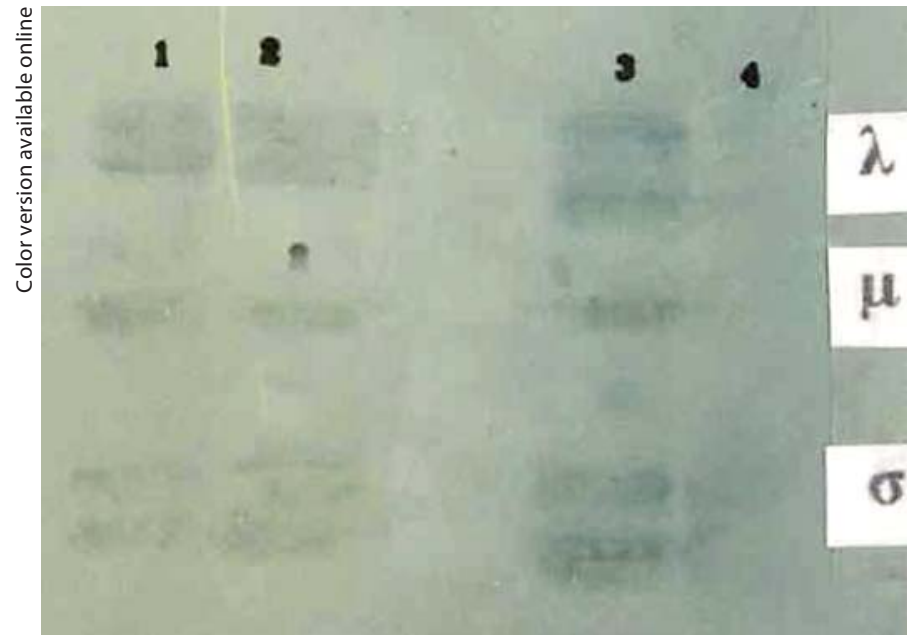

Fig. 4. Immunoblotting of viral proteins from $24 \mathrm{~h}$ coinfected cells. Protein bonds (lanes 1-3) were stained using reovirus antibody and lane 4 was stained using poliovirus antibody. Lane $1=$ Infected cell with reovirus; lane 2 = purified reovirus; lane $3=$ proteins from coinfected cells showing presence of reovirus proteins; lane 4 = proteins from coinfected cells, no poliovirus protein is present.

cause growth inhibition of poliovirus $[9,10]$. This kind of interference has a significant application value in certain systems. An example of such interference is the effect of enterovirus infection with live-attenuated poliovirus vaccine, which slows down the replication of vaccine virus inside the cells, resulting in inefficiency of vaccineinduced protection $[9,10]$. The other example is the effect of reovirus on environmental detection of enteroviruses [13].
In this study we wanted to test the interference between reovirus and poliovirus, which can coexist in the alimentary tract. We used vero cells for coinfection experiments, which support growth of both viruses. The results indicated a marked inhibition in poliovirus production in cells that were infected first with reovirus and then reinfected with poliovirus. When the harvest of coinfected cells was used to infect another set of cell monolayers (second passage), only reovirus was produced. Electron microscopy of the infected cell lysate revealed that only reovirus particles were present. This inhibitory effect was also observed in reovirus-infected cells $4 \mathrm{~h}$ postinfection. In a simultaneous infection of cells with reovirus and poliovirus it was observed that poliovirus replicated efficiently and resulted in cell lysis. The mechanism of reovirus inhibition of poliovirus growth was not at the level of receptor competition. Since poliovirus RNA did not replicate in reovirus-infected cells and since no poliovirus proteins synthesized in the presence of reovirus, it is tempting to speculate that the poliovirus growth inhibition was at the level of transcription. Further studies are required to reveal the exact mechanism of poliovirus inhibition.

\section{Acknowledgments}

The authors would like to thank The Iran University of Medical Sciences for financial support of this project. We also thank Mr. Hamidreza Mollaei for helping in viral load determination and Ms. Sara Mirhashemi, Ms. Maryam Fazeli and Mr. Amir Masoud Beheshti for typing the manuscript.

\section{References}

1 Whitaker-Dowling P, Youngner JS: Viral interference-dominance of mutant viruses over wild-type virus in mixed infections. Microbiol Rev 1987;51:179-191.

- 2 Rozinov MN, Fields BN: Interference of reovirus strains occurs between the stages of uncoating and dsRNA accumulation. J Gen Virol 1996;77:1425-1429.

-3 Huang AS: Defective interfering viruses. Annu Rev Microbiol 1973;27:101-117.

4 Perrault J: Origin and replication of defective interfering particles. Curr Top Microbiol Immunol 1981;93:151-207.
5 Ahmed R, Fields BN: Reassortment of genome segments between reovirus defective interfering particles and infectious virus: construction of temperature-sensitive and attenuated viruses by rescue of mutations from DI particles. Virology 1981;111:351363.

6 Keranen S: Interference of wild-type virus replication by an RNA-negative temperature-sensitive mutant of Semliki Forest virus. Virology 1977;80:1-11.
7 Bailly JE, Brown EG: Interference by a nondefective variant of influenza a virus is due to enhanced RNA synthesis and assembly. Virus Res 1998;57:81-100.

-8 Oie HK, Loh PC, Ratnayake RT: Studies on reovirus type 2: viral interference with UVinactivated virus. Arch Gesamte Virusforsch 1973;42:170-176

9 Fields B: Fields Virology, ed 35. Philadelphia, Lippincott-Raven, 2007.

10 Wheelock EF, Larke RP, Caroline NL: Interference in human viral infections: present status and prospects for the future. Prog Med Virol 1968;10:286-347. 
11 Frey S, Dagan R, Ashur Y, Chen XQ, Ibarra J, Kollaritsch H, Mazur MH, Poland GA, Reisinger K, Walter E, Van Damme P, Braconier JH, Uhnoo I, Wahl M, Blatter MM, Clements D, Greenberg D, Jacobson RM, Norrby SR, Rowe M, Shouval D, Simmons SS, van Hattum J, Wennerholm S, Gress JO, et al: Interference of antibody production to hepatitis B surface antigen in a combination hepatitis A/hepatitis B vaccine. J Infect Dis 1999; 180:2018-2022.

12 Nunen AB, Pontesilli O, Uytdehaag F, Osterhaus AD, de Man RA: Suppression of hepatitis $B$ virus replication mediated by hepatitis A-induced cytokine production. Liver 2001; 21:45-49.
13 Carducci A, Cantiani L, Moscatelli R, Casini B, Rovini E, Mazzoni F, Giuntini A, Verani M: Interference between enterovirus and reovirus as a limiting factor in environmental virus detection. Lett Appl Microbiol 2002;34:110-113.

14 Holland JJ, McLaren LC: Improved method for staining cell monolayers for virus plaque counts. J Bacteriol 1959;78:596-597.

15 Banerjea AC, Brechling KA, Ray CA, Erikson H, Pickup DJ, Joklik WK: High-level synthesis of biologically active reovirus protein $\sigma 1$ in a mammalian expression vector system. Virology 1988;167:601-612.
16 Laemmli UK: Cleavage of structural proteins during the assembly of the head of bacteriophage T4. Nature 1970;227:680-685.

17 Rozinov MN, Fields BN: Interference following mixed infection of reovirus isolates is linked to the M2 gene. J Virol 1994;68:66676671.

18 Urasawa T, Urasawa S, Kanamitsu M: Genetic stability of Sabin strain of type 3 poliovirus in the sensitivity to inhibitory bovine serum. I. Selection of inhibitory bovine serum against type 3 Sabin strain and sensitivity to the serum of vaccine progenies. Jpn J Med Sci Biol 1972;25:169-177. 